\title{
Low Temperature Synthesis of Rare-Earth Hexaborides for Solar Energy Conversion
}

\author{
Muhammad M. Hasan ${ }^{1,}$ a, Heber Sugo ${ }^{2}$ and Erich H. Kisi ${ }^{3}$ \\ 1, 2, ${ }^{3}$ University of Newcastle, Callaghan NSW 2308, AUSTRALIA.
}

\begin{abstract}
Thermionic energy conversion is an ideal way of converting concentrated solar energy into electricity. Developing suitable emitter/collector materials, with optimum work functions whilst being able to withstand elevated temperatures under high vacuum conditions, is a major challenge. Rare-earth hexaborides have great potential as thermionic emitters due to their superior chemical stability and low work function values, lanthanum hexaboride $(\phi \sim 2.60 \mathrm{eV})$ and cerium hexaboride $(\phi \sim 2.60 \mathrm{eV})$. This study forms part of a series of investigations aimed at developing rare-earth hexaboride cathode materials. Methods used to synthesise, characterise and fabricate these materials are discussed together with electron emission results.
\end{abstract}

\section{Introduction}

Using present state-of-art technologies, solar energy alone has the potential to generate 580TW to meet our energy demand [1]. Despite a great deal of research and development, current solar technologies are still expensive; require high maintenance and a large collection area. Thermionic energy conversion can transform heat directly to electricity using thermionic emission phenomena [2]. It is desirable to develop materials with low work function and high current density as emitters. The work function of a material is simply the potential energy required to release an electron from its surface into vacuum. Therefore, for a given temperature a low work function material will exhibit higher electron emission. Rare-earth hexaborides have been recognised as ideal emitter materials with lanthanum hexaboride as one of the best thermionic materials. Lanthanum hexaboride $\left(\mathrm{LaB}_{6}\right)$ shows high and stable DC (direct current) emission due to its low work function $(2.60 \mathrm{eV})$, high electrical conductivity, high melting point and superior chemical stability [3]. Cerium hexaboride $\left(\mathrm{CeB}_{6}\right)$ has also been reported as a potential thermionic emitter having similar low work function $(2.60 \mathrm{eV})$ and high emission current $[4,5]$.

Synthesis of hexaborides is difficult and requires high temperature processing. They can be prepared by a simple borothermal method in which their oxides are reduced by boron $[5,6]$. This solid-state reaction process requires very high temperatures $\left(1500-1700^{\circ} \mathrm{C}\right)$ and produces coarsegrained $\mathrm{LaB}_{6}$ and $\mathrm{CeB}_{6}$. Nanostructured lanthanum hexaboride has been reported to exhibit enhanced thermionic emission [7]. Recently, a wide variety of routes such as combustion synthesis [8], mechano-chemical synthesis [9], and vapor phase reaction [10] have been employed to synthesise $\mathrm{LaB}_{6}$ at reduced temperatures $\left(250-1200^{\circ} \mathrm{C}\right)$. The main drawback for most of these methods is that they require considerable post-synthesis treatment to obtain pure $\mathrm{LaB}_{6}$. The preparation of pure $\mathrm{LaB}_{6}$ or $\mathrm{CeB}_{6}$ at temperatures below $1300^{\circ} \mathrm{C}$ without any post-synthesis treatments using simple solid-state reactions is considered to represent a significant contribution to the present state-of-the-art approaches.

a Muhammad.Hasan@uon.edu.au

This is an Open Access article distributed under the terms of the Creative Commons Attribution License 2.0, which permits unrestricted use, distribution, and reproduction in any medium, provided the original work is properly cited. 
This study forms part of a series of investigations aimed at developing rare-earth hexaboride cathode materials. In the present work, a simple borothermal method has been utilized to synthesise $\mathrm{CeB}_{6}$ between $1100-1300^{\circ} \mathrm{C}$. The results are compared to those obtained for $\mathrm{LaB}_{6}$ in previous studies.

\section{Experimental details}

In this study, commercially available technical grade lanthanum oxide $\left(\mathrm{La}_{2} \mathrm{O}_{3}\right)$, cerium oxide $\left(\mathrm{Ce}_{2} \mathrm{O}_{3}\right)$ and poorly crystalline boron (B) were used as raw materials to synthesise $\mathrm{LaB}_{6}$ and $\mathrm{CeB}_{6}$. The simple borothermal method employs solid-state reactions in $\mathrm{La}_{2} \mathrm{O}_{3}-\mathrm{B}$ and $\mathrm{Ce}_{2} \mathrm{O}_{3}-\mathrm{B}$ blends to prepare $\mathrm{LaB}_{6}$ and $\mathrm{CeB}_{6}$ respectively. Firstly, powder blends having $10 \%$ excess boron were mixed with a ball-topowder ratio (4-5:1) for 30min in a SPEX8000 high-energy mill. Subsequently, the mixed powders were placed in a horizontal tube furnace for subsequent firings. The reaction processes were performed under a moderate vacuum (below $0.1 \mathrm{~Pa}$ ) at temperatures ranging from $1100-1300^{\circ} \mathrm{C}$ with 4 to $8 \mathrm{~h}$ holding periods.

The phases present in the samples were analyzed by X-ray diffraction (Philips X'pert MPD) using $\mathrm{CuK}_{\alpha}$ radiation $(\lambda=0.15406 \mathrm{~nm})$ and operating at an accelerating voltage of $40 \mathrm{kV}$ and emission current of $40 \mathrm{~mA}$ with a scan rate of $0.03^{\circ} / \mathrm{s}$ and step size $0.007^{\circ}$. Phase identification utilized the ICDD database. The crystallite size of the samples was calculated using Scherrer's equation,

$$
D=\frac{0.89 \lambda}{B \cos \theta}
$$

where $D$ is the mean crystallite diameter, $\lambda$ is the $\mathrm{X}$-ray wavelength , $B$ is the broadening of the fullwidth at half-maximum of the diffraction peak (FWHM), and $\theta$ is the diffraction angle.

Rietveld analysis of the XRD patterns was performed for data in the range between $20^{\circ}$ and $80^{\circ} 2 \theta$ using the Rietica software (Windows version 1.77) written by Hunter and Howard [11]. Quantitative Phase Analysis (QPA) was taken into account according to the method of Hill and Howard [12].

In a similar approach to previous studies, the surface morphology of samples was studied using a ZEISS Sigma Field Emission SEM (FESEM) and chemical composition by means of energy dispersive X-ray spectroscopy (EDS) were performed with a Bruker light element SSD (Silicon strip detector) EDS detector at accelerating voltages of 3-15kV. Finally, a simple Schottky diode apparatus was used to measure Richardson work function and emission constant of the cathode materials. Schottky and Richardson plots were used to find the Richardson work function of lanthanum hexaboride.

\section{Results and discussion}

The borothermal method produces highly volatile boron oxide (BO) as a by-product [6]. Therefore, a preliminary investigation was carried out to see the effect of excess boron on the quality of synthesised products. After firing, starting blends having $10 \%$ excess boron were found to produce higher mass proportion of $\mathrm{LaB}_{6}$ compared to the stoichiometric starting mix. Consequently, all samples were prepared from starting blends with $10 \%$ excess boron.

Figure 1(a) shows XRD patterns for some of typical $\mathrm{LaB}_{6}$ samples prepared at lower temperatures for different holding durations. All the patterns in the figure show distinct and sharp peaks of cubic lanthanum hexaboride having preferred orientation along (110) crystal planes. The samples prepared at a temperature $1250^{\circ} \mathrm{C}$ or below for 4 hours showed the presence of $\mathrm{LaBO}_{3}$ as the predominant minor phase. Lanthanum cyclo-triborate $\left(\mathrm{LaB}_{3} \mathrm{O}_{6}\right)$ and unreacted hydrated lanthanum oxide as $\mathrm{La}(\mathrm{OH})_{3}$ are also probably present in trace amounts. The samples prepared at $1250^{\circ} \mathrm{C}$ for 8 hours show the absence of any other distinct phases except for $\mathrm{LaB}_{6}$. From the figure, it can be inferred that pure $\mathrm{LaB}_{6}$ has been prepared at a temperature as low as $1250^{\circ} \mathrm{C}$ with an $8 \mathrm{~h}$ holding period. Synthesis of cerium hexaboride was also attempted via the same route. In contrast, pure $\mathrm{CeB}_{6}$ was produced at $1200^{\circ} \mathrm{C}$ with a $4 \mathrm{~h}$ holding duration as indicated in Figure 1(b). The expected intermediate phases $\mathrm{CeBO}_{3}$ and $\mathrm{CeB}_{3} \mathrm{O}_{6}$ were distinctly found in the sample prepared at $1100^{\circ} \mathrm{C}$.

The mean crystallite size for the $\mathrm{LaB}_{6}$ and $\mathrm{CeB}_{6}$ samples was calculated using Scherrer's equation taking instrumental broadening into consideration. Table 1 shows the variation of the mean crystallite 
size for different samples with temperatures. Both $\mathrm{LaB}_{6}$ and $\mathrm{CeB}_{6}$ final products were found to have mean grain size below one micron. The mean crystallite size for $\mathrm{LaB}_{6}$ and $\mathrm{CeB}_{6}$ samples prepared at $1250^{\circ} \mathrm{C}$ for 8 hours was found to be approximately $255( \pm 45) \mathrm{nm}$ and $240( \pm 40) \mathrm{nm}$ respectively.
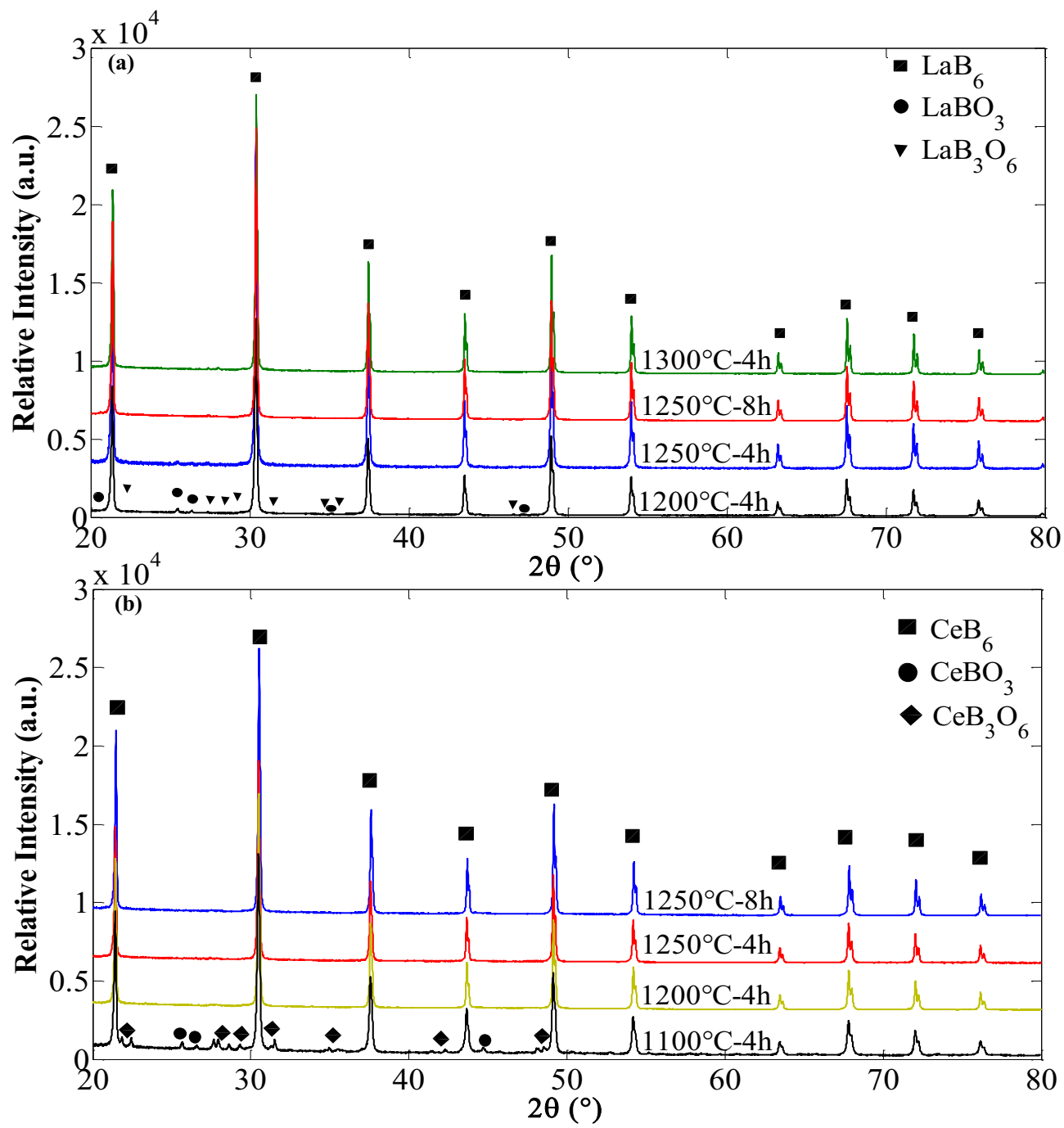

Figure 1. XRD patterns for the samples prepared using the simple borothermal method: (a) $\mathrm{LaB}_{6}$ and (b) $\mathrm{CeB}_{6}$.

Quantitative phase analyses for both hexaboride samples were performed based on the Rietveld refinements and are given in Table $1 . \mathrm{LaB}_{6}$ prepared at $1250^{\circ} \mathrm{C}$ for $8 \mathrm{~h}$ is found to have purity above $99 \%$ (by mass), while $\mathrm{CeB}_{6}$ of similar quality can be produced at a temperature as below as $1200^{\circ} \mathrm{C}$. It is also noted for $\mathrm{CeB}_{6}$ synthesis that the sample fired at $1100^{\circ} \mathrm{C}$ was found to contain $78 \%$ cerium hexaboride (by mass).

Microstructural morphology was investigated for the pure $\mathrm{LaB}_{6}$ and $\mathrm{CeB}_{6}$ prepared at $1300^{\circ} \mathrm{C}$ and $1250^{\circ} \mathrm{C}$ using SEM. Secondary electron images are shown in Figure 2. From the figure, the growth of cubic single nanocrystals of $\mathrm{LaB}_{6}$ and $\mathrm{CeB}_{6}$ is clearly observable. The size of the cubic crystals in the micrographs ranges from $100 \mathrm{~nm}$ to a few microns. This is in good agreement with the calculated mean crystallite size of the hexaboride samples mentioned earlier. Sintering of some particles is shown by the enclosed area for $\mathrm{LaB}_{6}$. EDS analyses confirm that both hexaborides were free from any impurities. 
Table 1 Variation of mean crystallite size and percent conversion by mass for synthesised products with firing temperatures.

\begin{tabular}{lcc|cc}
\hline Temperature & \multicolumn{2}{c|}{ Mean crystallite size $(\mathrm{nm})$} & \multicolumn{2}{c}{ Percent conversion by mass $(\%)$} \\
\cline { 2 - 5 }$\left({ }^{\circ} \mathrm{C}\right)$ & LaB6 & CeB6 & LaB6 & CeB6 \\
\hline 1100 & - & $105( \pm 20)$ & - & 77.5 \\
1200 & $150( \pm 20)$ & $185( \pm 30)$ & 97.5 & 99.7 \\
1250 & $235( \pm 20)$ & $195( \pm 25)$ & 98.5 & 99.7 \\
$1250 \mathrm{a}$ & $255( \pm 45)$ & $240( \pm 40)$ & 99.0 & 99.7 \\
1300 & $300( \pm 50)$ & - & 99.0 & - \\
\hline
\end{tabular}

a the sample fired for $8 \mathrm{~h}$
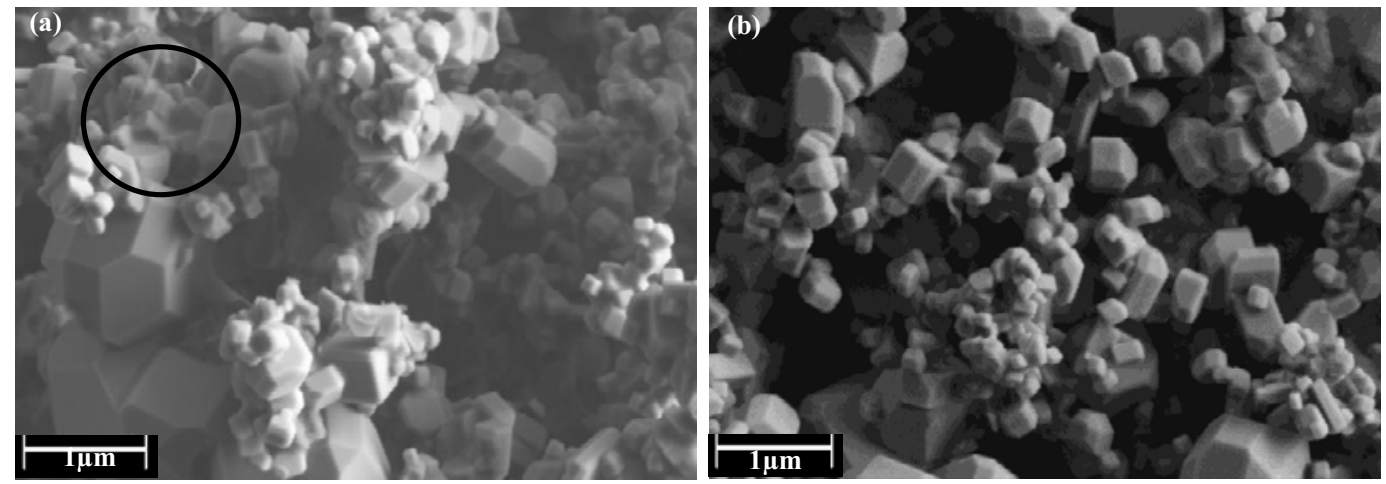

Figure 2. Secondary electron images: (a) $\mathrm{LaB}_{6}$ fired at $1300^{\circ} \mathrm{C}$ and (b) $\mathrm{CeB}_{6}$ fired at $1250^{\circ} \mathrm{C}$ for $4 \mathrm{~h}$.

Thermionic emission measurements were carried out for a $\mathrm{LaB}_{6}$ cathode sintered at $1900^{\circ} \mathrm{C}$. Figure 3(a) \& (b) show the Schottky plot (Ln (emission current density, J) versus square root of emitter-collector voltage, $\mathrm{V})$ and Richardson plot $\left(\operatorname{Ln}\left(\mathrm{J}_{0} / \mathrm{T}^{2}\right)\right.$ versus $\left.1000 / \mathrm{T}\right)$, respectively. The slope of the Richardson plot was used to find the Richardson work function which was found to be $2.86 \mathrm{eV}$. From its intercept, emission constant was calculated to $10.4 \mathrm{Acm}^{-2} \mathrm{~K}^{-2}$. This measured work function and emission constant is in well agreement with values $\left(2.64 \mathrm{eV}\right.$ and $\left.29 \mathrm{Acm}^{-2} \mathrm{~K}^{-2}\right)$ reported in the literature $[3,13]$. Thermionic emission tests to determine the properties of cerium hexaboride cathodes are currently underway.
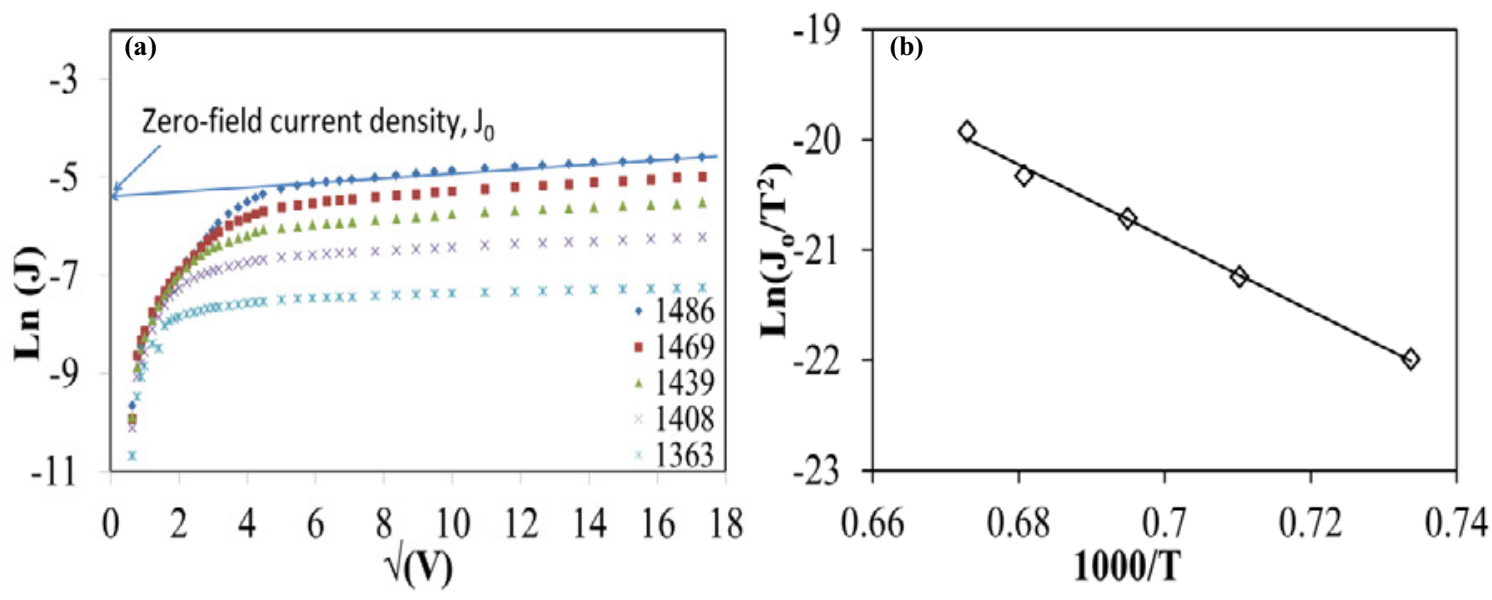

Figure 3. (a) Schottky plots at different temperatures (K) and (b) Richardson plot for a typical LaB6 sample prepared using the borothermal method. 


\section{Conclusion}

In the present work, the simple borothermal route has been described to prepare pure $\mathrm{LaB}_{6}$ and $\mathrm{CeB}_{6}$ at temperatures lower than those previously reported. $\mathrm{XRD}$ patterns show that pure $\mathrm{LaB}_{6}$ was prepared at a temperature as low as $1250^{\circ} \mathrm{C}$, whereas, pure $\mathrm{CeB}_{6}$ was produced at $1200^{\circ} \mathrm{C}$. The hexaboride samples were found to have purities $\geq 99 \%$ (by mass) using Rietveld analysis. At lower temperatures, the method mainly exhibits the presence of two types of borates, such as, $\mathrm{LaBO}_{3} / \mathrm{LaB}_{3} \mathrm{O}_{6}$ (for $\mathrm{LaB}_{6}$ synthesis) and $\mathrm{CeBO}_{3} / \mathrm{CeB}_{3} \mathrm{O}_{6}$ (for $\mathrm{CeB}_{6}$ synthesis). From secondary electron images, nanostructured particles having about similar size were observed for both hexaborides. From thermionic emission measurements, the Richardson work function and emission constant of the prepared $\mathrm{LaB}_{6}$ sample were found to be $2.86 \mathrm{eV}$ and $10.4 \mathrm{Acm}^{-2} \mathrm{~K}^{-2}$. This low work function and nanosized crystallites make these materials ideal candidates to be used in solar thermionic energy converters.

\section{Acknowledgements}

The authors gratefully acknowledge the financial support given by the Australian Renewable Energy Agency (Grant No.1-A065) as well as an Australian Postgraduate Award and Tuition Fee Scholarship for Muhammad M. Hasan. The authors also acknowledge help and support from David Phelan and Jennifer Zobec in the Electron Microscope \& X-ray Unit and from Dylan Cuskelly and Anthony Rawson in the Structure of Advanced Materials Group, the University of Newcastle.

\section{References}

[1] M. Z. Jacobson, M. A. Delucchi, Providing all global energy with wind, water, and solar power, Part I: Technologies, energy resources, quantities and areas of infrastructure, and materials, Energy Policy 39, pp. 1154-1169 (2011).

[2] C. Herring, M.H. Nichols, Thermionic Emission, Rev. Mod. Phys. 21, pp. 185-270, (1949).

[3] J. M. Lafferty, Boride Cathodes, J. Appl. Phys. 22, pp. 299-309, (1951).

[4] J. Q. Xu, T. Mori, Y. Bando, D. Golberg, D. Berthebaud, A. Prytuliak, Synthesis of CeB 6 thin films by physical vapor deposition and their field emission investigations, Mater. Sci. Eng. B 177, pp. 117-120, (2012).

[5] T. Tanaka, R. Nishitani, C. Oshima, E. Bannai, S. Kawai, The preparation and properties of CeB, $S m B_{6}$, and $G d B_{6}$, J. Appl. Phys. 51, pp. 3877-3883, (1980).

[6] G.V. Samsonov, Y.B. Paderno, V.S. Fomenko, Hexaborides of the rare-earth metals, Powder Metall. Met. Ceram. 2, pp. 449-454, (1963).

[7] L.H. Bao, J.X. Zhang, S.L. Zhou, Y.F. Wei, Preparation and characterization of grain size controlled LaB 6 polycrystalline cathode material, Chin. Phys. Lett. 27, pp. 1-4, (2010).

[8] Z.H. Dou, T.A. Zhang, Z.Q. Zhang, H.B. Zhang, J.C. He, Preparation and characterization of $\mathrm{LaB}_{6}$ ultra fine powder by combustion synthesis, Trans. Nonferrous Met. Soc., 21, pp. 1790-1794, (2011).

[9] D. Agaogullari, I. Duman, M.L. Ovecoglu, Synthesis of $\mathrm{LaB}_{6}$ powders from $\mathrm{La}_{2} \mathrm{O}_{3}, \mathrm{~B}_{2} \mathrm{O}_{3}$ and $\mathrm{Mg}$ blends via a mechanochemical route, Ceram. Int. 38, pp. 6203-6214, (2012).

[10] J.Q. Xu, Y.M. Zhao, C.Y. Zou, Self-catalyst growth of LaB 6 nanowires and nanotubes, Chem. Phys. Lett. 423, pp. 138-142, (2006).

[11] B.A. Hunter, C.J. Howard, http://www.ccp14.ac.uk/.

[12] R.J. Hill, C.J. Howard, Quantitative phase analysis from neutron powder diffraction data using the Rietveld method, J. Appl. Crystallogr. 20, pp. 467-474, (1987).

[13] M. Hasan, H. Sugo, E. Kisi, Low temperature carbothermal and boron carbide reduction synthesis of LaB, J. Alloy. Comp. 578, pp. 176-182, (2013). 